\title{
De voorstellen van de Commissie Stevens
}

\author{
Drs. P. Kavelaars
}

\section{Inleiding}

Afgelopen zomer heeft de Commissie Stevens haar rapport met voorstellen tot vereenvoudiging van de belastingwetgeving en verlaging van de belastingdruk aan de staatssecretaris van Financiën overhandigd. Inmiddels heeft de staatssecretaris begin november aan een aantal adviesorganen, waaronder de SER, de Stichting van de Arbeid en de Sociale Verzekeringsraad advies gevraagd over de voorstellen. Uit die adviesaanvragen kan geconstateerd worden dat er nog wel de nodige problemen aan de voorstellen kleven en dat er de nodige scepsis bestaat of onverkorte invoering wel mogelijk is. Zoals hierna zal blijken, zijn er inderdaad de nodige knelpunten te signaleren die niet zo erg gemakkelijk oplosbaar zijn. Anderzijds bevat het rapport ook een aantal ideeën die zonder veel complicaties vrij snel kunnen worden ingevoerd, met name waar het de uitvoeringssfeer betreft. In dit verband is van belang dat in tegenstelling tot wat de Commissie met de titel van het rapport ('Graag of niet') suggereert, het bepaald niet noodzakelijk is om voor een 'alles of niets' benadering te kiezen. Sterker nog, het is zelfs wenselijk enkele onderdelen eruit te lichten en die zo spoedig mogelijk in te voeren, terwijl daarentegen andere voorstellen beter niet overgenomen kunnen worden, c.q. nadere bestudering vergen. In deze bijdrage worden de belangrijkste punten van de voorstellen van de Commissie Stevens besproken.

\section{De achtergrond}

De instelling van de Commissie Stevens in 1990 mag gerust verrassend worden genoemd. Immers, met ingang van dat jaar was juist de Oort-operatie in wetgeving omgezet en deze Oort-wetgeving werd veelvuldig aangeduid als de grootste (en laatste?) belastingvereenvoudiging van deze eeuw. Nu is reeds tijdens de totstandkoming van de Oort-wetgeving gebleken dat op een aantal punten vereenvoudigingen zijn aangebracht, doch dat er even zo vele complicaties voor in de plaats zijn gekomen. De twee onderdelen die wat dat betreft de meeste aandacht trokken, zijn ongetwijfeld de gemengde-kostenproblematiek en de overhevelingstoeslag. Kort daarna is bovendien nog een belangrijke verzwaring van de uitvoeringspraktijk ontstaan doordat in de sfeer van het reiskostenforfait voor woonwerkverkeer voortaan rekening dient te worden gehouden met de wijze waarop men reist (openbaar vervoer of eigen vervoer). Weliswaar was deze maatregel niet door de Commissie Oort voorgesteld, ze vormde wel een logisch vervolg op het Oortse wetgevingsproces.

Inmiddels heeft het ministerie van Financiën in november 1991 een tussenrapportage gepubliceerd met betrekking tot de waardering voor de Oortwetgeving. Hieruit blijkt dat de Oortwetgeving zeker niet alom wordt gewaardeerd. Integendeel, zo kan wel geconcludeerd worden. Weliswaar wordt de tariefstructuur eenvoudiger genoemd (vooral ook door het ineenschuiven van belasting en premieheffing), maar daar staan

Drs. P. Kavelaars, directeur van het Wetenschappelijk Bureau van TRN/Begheyn \& Sneep Melse te Rotterdam en wetenschappelijk medewerker bij de vakgroep Fiscale Economie van de Erasmus Universiteit Rotterdam. 


\section{MAB}

belangrijke nadelen tegenover (bijvoorbeeld de kostenaftrekbeperkingen en de overhevelingstoeslag). Bovendien is men in doorsnee van mening dat er uiteindelijk geen sprake is van een (substantiële) belastingverlaging. Al met al is het dus de vraag of de hele operatie de moeite wel waard is geweest.

Reeds tijdens de parlementaire behandeling van de Oortvoorstellen werd een aantal Tweede Kamerleden zich al bewust van de praktische problemen die zouden opduiken; zij uitten de wens een nieuwe vereenvoudigingscommissie in te stellen. De staatssecretaris is daaraan in het voorjaar van 1990 tegemoet te komen door de Commissie Stevens te installeren. Deze Commissie heeft in een periode van ruim een jaar een omvangrijke hoeveelheid werk verricht. Reeds op 3 juli 1991 kon zij haar voorstellen presenteren. Deze voorstellen brengen bij onverkorte doorvoering op een aantal terreinen ingrijpende aanpassingen met zich mee. Of die aanpassingen alle even wenselijk zijn is overigens nog zeer de vraag. De indruk bestaat dat de commissie weliswaar zeer snel gewerkt heeft, maar daardoor toch op enkele punten te gemakkelijk over de complicaties die onmiskenbaar aan haar voorstellen verbonden zijn, is heen gelopen dan wel deze niet heeft onderkend. Met name het globale karakter van het rapport roept hier en daar twijfels op. Niettemin is één van de voorstellen zeer zeker van zeer groot belang: door de verdere samenvoeging in de uitvoering van de loonheffing en de premieheffing werknemersverzekeringen kan een omvangrijke vereenvoudiging en kostenbesparing worden bereikt. Met name ten aanzien van dit gedeelte van de voorstellen is het wenselijk dat het zo spoedig mogelijk wordt ingevoerd.

\section{Grondslagverbreding en tariefverlaging}

a Inleiding

Een van de onderdelen van de opdracht van de Commissie Stevens was te bezien of een verdergaande tariefverlaging haalbaar was onder een gelijktijdige verbreding van de heffingsgrondslag. De Commissie Oort heeft op dit punt goed kunnen scoren door voor te stellen de premies volks- verzekeringen voortaan niet meer op het fiscale inkomen in aftrek toe te laten. De ruimte voor de Commissie Stevens leek daardoor sterk beperkt. Door zich echter niet alleen toe te leggen op loonen inkomensheffing maar ook de premieheffing werknemersverzekeringen in haar beschouwingen te betrekken, kon zij beide heffingen in onderling verband beoordelen.

De premieheffing werknemersverzekeringen wordt in grote lijnen langs dezelfde weg geheven als de loonheffing. Er zijn echter enkele verschillen. In de eerste plaats is daar de heffende instantie: de premies werknemersverzekeringen worden geheven door de bedrijfsvereniging. In de tweede plaats bestaat er een aantal verschillen tussen de loonbegrippen waarover premies, respectievelijk loonheffing wordt geheven. Door deze twee heffingen zoveel mogelijk in elkaar te schuiven, kunnen drie voordelen worden behaald:

- de heffingsgrondslag wordt verbreed, waardoor lagere tarieven mogelijk zijn;

- de werkgever wordt niet meer geconfronteerd met loonelementen die voor de ene heffing wel loon vormen en voor de andere heffing niet;

- de werkgever heeft voortaan nog maar met één heffingsbevoegde instantie te maken.

Aldus beschouwd lijken er alleen maar voordelen verbonden te zijn aan het ineenschuiven van beide heffingen. Dat is echter niet geheel waar. Met name de hierna te bespreken, naar het oordeel van de Commissie Stevens daartoe noodzakelijke maatregelen, leiden tot complicaties of roepen anderszins bezwaren op.

b Afschaffing aftrekbaarheid premies werknemersverzekeringen

De werknemersaandelen in de premies werknemersverzekeringen zijn fiscaal aftrekbaar; dat geldt uiteraard niet voor de berekening van de verschuldigde premies werknemersverzekeringen zelf. De Commissie stelt daarom voor de aftrekbaarheid in de fiscaliteit af te schaffen. Het belangrijkste argument is dat daarmee de eenvoud wordt gediend. Dat argument is echter nogal oneigenlijk. De aftrekbaarheid van de pre- 


\section{MAB}

mies is in de praktijk geheel geen probleem. Een duidelijk bezwaar van het voorstel is dat er een soort dubbele heffing door plaatsvindt: de premies zijn fiscaal niet aftrekbaar, maar de uitkeringen zijn wel volledig belast. Bovendien is er sprake van een weglekeffect: de afschaffing van de aftrekbaarheid van premies werknemersverzekeringen gaat ten nadele van één categorie belastingplichtigen, te weten de werknemers. De daarmee te financieren tariefverlaging komt echter een ieder ten goede. De Commissie Stevens heeft dit effect uiteraard onderkent en stelt daarom een scala van maatregelen voor die het voordeel van de diverse categorieën niet-werknemers dienen te neutraliseren. Deze maatregelen zijn van zeer diverse aard en vertonen in zekere zin een 'hap-snap-karakter'. Zeker na enige tijd zal het verband tussen de afschaffing van de aftrekbaarheid van de premies werknemersverzekeringen en deze 'neutraliseringsmaatregelen' niet meer zijn vast te stellen.

Ook anderszins is een kanttekening op haar plaats; deze is overigens van meer algemene aard omdat ze ook geldt voor een aantal andere maatregelen die de Commissie voorstelt. De grondslagverbreding leidt weliswaar tot een tariefverlaging, maar niet tot een vermindering van de belasting- en premiedruk. En men kan zich dan afvragen wat daarvan het voordeel is.

\section{c Afschaffing overhevelingstoeslag}

Een tweede door de Commissie Stevens in dit verband voorgestelde maatregel betreft het afschaffen van de overhevelingstoeslag. Deze overhevelingstoeslag is tot stand gekomen bij de invoering van de Oortwetgeving. ledere werknemer heeft recht op de toeslag die door de werkgever wordt verstrekt. De toeslag is een gevolg van het feit dat in de vóór-Oortse situatie de zogenoemde opslagpremies AAW/AWBZ voor rekening van de werkgever kwamen, doch nu worden gedragen door de werknemer. Ter compensatie van die lastenverzwaring bij de werknemers dient de werkgever de overhevelingstoeslag te betalen. Deze overhevelingstoeslag is onderworpen aan de loonheffing, maar niet aan de heffing van premies werknemersverzekeringen. Dat is weinig praktisch. Ook in een aantal andere opzichten wordt de overhevelingstoeslag niet als loon beschouwd (bijvoorbeeld voor de pensioengrondslag). Deze overhevelingstoeslag levert enkele problemen op; de Commissie stelt daarom voor hem af te schaffen. Daarmee kan dan tevens bereikt worden dat het loonbegrip voor de premieheffing werknemersverzekeringen en dat voor de loonheffing weer dichter naar elkaar groeien.

Het onderhavige voorstel is zowel begrijpelijk als merkwaardig. Begrijpelijk omdat het inderdaad een aantal voordelen oplevert de overhevelingstoeslag af te schaffen; merkwaardig, omdat ten tijde van de totstandkoming van de Oort-wetgeving de problematiek diepgaand bediscussieerd is en niet heeft geleid tot een oplossing. De Commissie Stevens komt evenmin met een alternatief, maar meent wel dat afschaffing ervan zonder problemen moet kunnen. Daarbij gaat ze er vanuit dat via een paraplu-wetje de opwaartse druk op pensioenen kan worden voorkomen. Daarmee blijft natuurlijk wel het probleem bestaan dat de overhevelingstoeslag als zodanig herkenbaar moet blijven. In zoverre treedt er geen verbetering op ten opzichte van de huidige wetgeving. Teneinde grote problemen te voorkomen is de vraag gerezen of de overhevelingstoeslag niet in fasen kan worden afgeschaft. Dat lijkt immers eenvoudiger. Enigszins tot mijn verbazing maakt de Commissie daaromtrent geen enkele opmerking.

\section{dAfschaffing WAO-franchise}

Een derde belangrijk onderdeel van de voorstellen van de Stevens die moeten leiden tot een eenvoudiger heffing, een bredere grondslag en een lager tarief, betreft de afschaffing van de WAOfranchise. De WAO-franchise is een soort premievrije som waarover geen WAO-premie wordt geheven. Momenteel bedraagt de franchise $f$ 98,- per dag. Alleen hetgeen per dag meer wordt verdiend dan $f 98,-$ is onderworpen aan de premieheffing voor de WAO. De achtergrond van de WAO-franchise is als volgt: Degene die arbeidsongeschikt wordt, is gerechtigd tot een AAW-uitkering die op minimumniveau wordt verstrekt. De arbeidsongeschikte werknemer heeft 


\section{MAB}

recht op een uitkering tot $70 \%$ van zijn laatstgenoten loon. Indien dit meer is dan de AAW-uitkering wordt deze AAW-uitkering aangevuld met de WAO-uitkering tot de 70\%-norm. Omdat iedereen premie AAW betaalt, is het niet redelijk dat ook over het volle inkomen premie WAO is verschuldigd. Door toepassing van de WAO-franchise wordt dit voorkomen.

De Commissie Stevens heeft voorgesteld de WAO-franchise af te schaffen, omdat deze in de praktijk teveel problemen zou opleveren. Daarnaast wordt aldus een aanzienlijke verbreding verkregen van de grondslag waarover de WAOpremie wordt geheven, zodat de WAO-premie fors verlaagd kan worden, hetgeen de Commissie als een pluspunt ervaart. Dit laatste is natuurlijk maar zeer betrekkelijk: er treedt immers ook hier geen drukverlaging op. Maar ook anderszins zijn er bezwaren aan te voeren tegen het voorstel van de commissie: enerzijds ontstaat door het afschaffen van de WAO-franchise dubbele premieheffing (AAW en WAO) waartegenover geen additionele uitkeringsrechten ontstaan. Anderzijds is de argumentatie die de commissie hanteert niet correct: de WAO-franchise levert namelijk in de praktiik van de loonadministratie nauwelijks een probleem op. Het verdient dan ook zeker geen aanbeveling om op dit punt het voorstel van de Commissie op te volgen.

\section{Vereenvoudigingen en grondslagverbreding in de loonsfeer}

De drie in kwantitatief opzicht meest opvallende grondslagverbredingen zijn hiervoor aan de orde geweest. Daarnaast is op dit vlak nog een aantal minder verstrekkende voorstellen gedaan. Deze zijn primair gericht op vereenvoudiging van de wetgeving. Soms echter wordt daar nog een ander doel bij nagestreefd. Hierna passeren deze vereenvoudigingen in vogelvlucht de revue.

\section{a Aanpassing van het arbeidskostenforfait}

Teneinde het aantrekkelijker te maken tot de arbeidsmarkt toe te treden, stelt de commissie voor het abreidskostenforfait bij inkomsten uit tegenwoordige dienstbetrekking op te hogen tot $5 \%$. Deze maatregel behoeft geen nadere bespreking meer, omdat dit voorstel reeds per 1 januari 1992 is geëffectueerd.

\section{b Vervallen van het reiskostenforfait}

Haaks op het voorstel tot verhoging van het arbeidskostenforfait staat het voorstel tot afschaffing van het reiskostenforfait. Vanuit vereenvoudigingsoogpunt is dat voorstel zeer begrijpelijk, doch vanuit het arbeidsmarktbeleid daarentegen niet. Immers, wanneer de reiskosten tussen woning en arbeidsplaats fiscaal niet meer in aanmerking kunnen worden genomen, zal dit in beginsel negatieve effecten hebben op de toetreding tot de arbeidsmarkt. Het lijkt dan ook niet erg verstandig om het reiskostenforfait af te schaffen.

Wel is het wenselijk dat de thans geldende regeling weer begrijpelijk wordt. Daartoe dient het onderscheid tussen de openbaar-vervoertabellen en de algemene tabellen te vallen. Dat overigens de eventuele afschaffing van het reiskostenforfait de nodige voeten in de aarde zal hebben, kan al worden afgeleid uit het in het najaar 1991 gedane voorstel om tot een geringe verlaging van het forfait te komen. Deze riepen bij de parlementaire behandeling een storm van protest op.

Naar ik meen dient het forfait gehandhaafd te worden, doch dient het onderscheid dat daarbij gemaakt wordt al naar gelang de wijze van vervoer te vervallen. Deze in augustus 1990 aangebrachte nuancering blijkt nog steeds veel weerstand op te roepen. Ook uit de tussentijdse evaluatie van de Oort-voorstellen kan dat worden afgeleid.

\section{c Het autokostenforfait}

Degene aan wie een auto ter beschikking is gesteld en deze mag gebruiken voor privédoeleinden wordt belast voor het zogenoemde autokostenforfait. De Commissie Stevens stelt in de eerste plaats voor het forfait te verhogen, waarbij zij zich met name baseert op de daadwerkelijke kosten van het privégebruik en het feit dat door het afschaffen van het reiskostenforfait ook de woon-werkkilometers voortaan als privé gelden. Het vreemde is dat deze laatste overweging voor ondernemers geen rol kan spelen omdat zij met 


\section{MAB}

woon-werkverkeer in fiscale zin niets te maken hebben. Overigens wordt het aldus herrekende forfait vanwege inkomenspolitieke redenen naar beneden afgerond; de commissie komt dan tot een forfait van $28 \%$. Dat is in elk geval 4 tot $8 \%$ punten hoger dan het huidige forfait. In de tweede plaats, maar dit leidt niet tot een grondslagverbreding, is de commissie van mening dat het autokostenforfait ook in de loonsfeer in aanmerking moet worden genomen. Tot op heden is dit idee steeds afgeketst op de daaraan verbonden administratieve moeilijkheden die voor de werkgever zouden optreden. Nu lijken die problemen wel mee te vallen; anderszins bestaat er ook weinig bezwaar tegen het huidige systeem waarbij het ter beschikking hebben van 'een auto van de zaak' tot een verplichte aanslag in de inkomstenbelasting leidt. Vanuit de gedachte dat er naar gestreefd moet worden de administratieve lasten van werkgevers zoveel mogelijk te beperken, is handhaving van de status quo het meest wenselijk.

\section{d Diversen}

De Commissie Stevens heeft een aantal voorstellen gedaan die slechts van geringe betekenis zijn voor de eenvoudsdoelstelling. Ook budgettair is het belang ervan gering. Hieronder zijn ze voor de volledigheid op een rijtje gezet:

1 de vergoeding voor algemene ziektekosten dient in de premieheffing werknemersverzekeringen te worden betrokken. Daardoor wordt de heffingsgrondslag verbreed, terwijl tegelijkertijd op dit punt het huidige verschil tussen de premieheffing werknemersverzekeringen en de loonheffing ongedaan wordt gemaakt;

2 de geschenkenregeling, inhoudende dat maximaal vijf keer per jaar een bedrag van $f$ 110,onbelast mag worden verstrekt bij feestdagen dient naar het oordeel van de Commissie te vervallen, omdat er niet langer een gegronde reden meer voor een dergelijke regeling is aan te voeren. Dit lijkt mij niet juist; in het bedrijfsleven speelt de geschenkenregeling in het arbeidsvoorwaardenkader van vele ondernemingen een belangrijke rol. Het tweede door de Commissie naar voren gehaalde argument, te weten grondslagverbreding, dient daar naar mijn oordeel zonder meer voor te wijken;

3 ook de bedriifsspaaregelingen wenst de Commissie op te heffen. Zij baseert zich daarbij met name op de ingewikkeldheid van de regelingen. Dat valt echter wel mee. Bovendien geldt ook hier dat de bedrijfsspaaregelingen in het kader van de arbeidsvoorwaarden vaak een belangrijke rol spelen;

4 vakantiebonnen dienen voortaan tegen 100\% in de heffing te worden betrokken, in plaats van $75 \%$ nu. Tegen dit voorstel kan weinig bezwaar bestaan, nu de ratio van de lagere waardering slechts zeer beperkt is. Overigens had de Commissie Oort toentertijd hetzelfde voorstel gedaan.

De meeste van de hiervoor vermelde aanpassingen zijn mede (naast grondslagverbreding of vereenvoudiging) van belang voor de grondslaguniformering tussen loonheffing en premieheffing werknemersverzekeringen. Daarnaast is er nog de voorgestelde aanpassing ten aanzien van de beschikking loonbelasting; die heeft alleen betekenis voor de uniformering. Deze aanpassing is van belang in verband met het feit dat bij de berekening van de verschuldigde loonheffing rekening kan worden gehouden met bepaalde aftrekposten; deze aftrekposten spelen bij de premieheffing werknemersverzekeringen geen rol, zodat de beschikking daar ook niet aan de orde komt. Teneinde de grondslag voor beide heffingen gelijk te trekken, wordt in de voorstellen de beschikking omgebouwd van een aftrek op het inkomen, tot een aftrek op de verschuldigde belasting. Dit voorstel kan in beginsel zonder veel problemen worden ingevoerd; wel kan zich een tariefkwestie voordoen doordat de inkomensaftrek immers omgerekend moet worden naar een belastingaftrek en wel tegen het voor de belastingplichtige geldende marginale percentage. Hierdoor ontstaat een enigszins complexere regeling. De vraag is overigens of de ombouw van een inkomensaftrek naar een belastingaftrek echt nodig is teneinde voldoende onderlinge afstemming tussen de inkomensbegrippen te verkrijgen. Naar ik meen is dat niet het geval. 


\section{MAB}

\section{Grondslagverbreding en vereenvoudigingen in de aanslagsfeer}

De hiervoor beschreven verbredingen van de heffingsgrondslag vinden hun grond primair in de inhoudingssfeer; via artikel 22 Wet IB 1964 werken zij door naar de aanslagsfeer. Daarnaast stelt de Commissie nog een aantal wijzigingen voor die uitsluitend de aanslagsfeer (inkomensheffing) treffen. Ook bij deze wijzigingen gaat het om vereenvoudiging en/of grondslagverbreding. De meeste van de voorgestelde wijzigingen zijn van zeer beperkte betekenis en behoeven ook nauwelijks commentaar:

- verlagen van de zelfstandigenaftrek in de winstsfeer;

- op nihil stellen van de vermogensaftrek. Deze aftrek beoogt tegemoet te komen aan het feit dat onder de Nederlandse belastingheffing inflatiewinsten belast worden. Het is opmerkelijk dat in een tijd van een stijgend inflatiecijfer voorgesteld wordt de aftrek terug te brengen. Overigens kan uit de historie van de belastingheffing worden afgeleid dat inflatiecompenserende maatregelen een min of meer anticyclisch verloop hebben. In die zin is het voorstel van Stevens c.s. geen uitzondering;

- verhoging van het huurwaardeforfait. Dit voorstel was toen het rapport werd gepresenteerd reeds achterhaald door een in werking getreden wet;

- het beperken of afschaffen van de rente- en dividendvrijstelling. Dit voorstel is zeer merkwaardig wanneer men in aanmerking neemt om welke redenen toentertijd de vrijstellingen zijn ingevoerd. Wat betreft de rentevrijstelling werd beoogd aldus tegemoet te komen aan de inflatiefactor. De dividendvrijstelling is ooit ingevoerd met het oog op het bevorderen van het beleggen in Nederlands risicovermogen. De beperking van deze twee vrijstellingen heeft de Commissie eigenlijk alleen nodig voor de financiering van de tariefverlaging. Andere gegronde redenen zijn er niet. Integendeel, een nadeel is ongetwijfeld dat het aantal op te leggen aanslagen zal toenemen. Bij elkaar is er dus weinig reden dit onderdeel van de voorstellen over te nemen;
- een laatste belangrijk voorstel betreft de afschaffing van de aftrek van consumptieve rente (rente op leningen die zijn aangegaan voor andere doeleinden dan voor inkomensverwerving). Deze rente is momenteel aftrekbaar als persoonlijke verplichting. De Commissie heeft hierbij wederom als belangrijkste argument de budgettaire opbrengst laten wegen. Het belangrijkste probleem dat hierbij om de hoek komt kijken is de afbakening tussen consumptieve rente en hypothecaire rente. Deze laatste blijft immers wel fiscaal aftrekbaar. Hier zullen zich nagenoeg onoplosbare complicaties gaan voordoen, zodat ook dit onderdeel van de voorstellen beter niet kan worden ingevoerd.

Naast deze posten zijn er nog enkele andere kosten waarvan de aftrek naar het oordeel van de Commissie beperkt dient te worden. Deze zijn echter nauwelijks van belang zodat daaraan voorbij wordt gegaan.

\section{De tariefstructuur}

\section{a Inleiding}

De verbreding van de heffingsgrondslag zoals die voortvloeit uit de in de paragrafen 3 en 4 beschreven maatregelen heeft als voornaamste doel een tariefverlaging mogelijk te maken. De 'opbrengst' van de grondslagverbreding heeft de Commissie berekend op ruim $f 10,5$ miljard; daarvan is een gedeelte door de regering overigens al 'verbruikt' (bijvoorbeeld de opbrengst van de verhoging van het huurwaardeforfait), zodat het uiteindelijk beschikbare bedrag lager ligt dan $f 10$ miljard. Het gevolg van deze uitwisseling tussen heffingsgrondslag en tarieven is wel dat de belastingdruk zelf zich niet wijzigt; slechts de percentages worden aangepast. ledere belastingplichtige betaalt derhalve zijn eigen tariefverlaging. Het is de vraag of we hier erg veel mee opschieten.

De Commissie stelt in de tariefsfeer niet alleen voor te komen tot lagere percentages, maar evenzeer tot een vermindering van het aantal tariefschijven; een spectaculaire verlaging van negen tot drie tariefschijven, zoals door Oort is gereali- 


\section{MAB}

seerd, was uiteraard niet meer mogelijk. De Commissie heeft er dan ook slechts één tariefschijf afgekregen. En eigenlijk is zelfs dat niet eens geheel gelukt omdat een van de tariefschijven in de nieuwe structuur in feite bestaat uit twee tariefschijven. Of met deze aanpassing nu zoveel vereenvoudigingswinst wordt behaald - zoals de Commissie meent - is nog maar de vraag. Het huidige drie schijventarief is overzichtelijk en we lopen daarmee zeker ook niet uit de pas met de ons omringende landen. Naast de aanpassing van de tariefschijven wordt tevens voorgesteld de belastingvrije sommen om te zetten in belastingcredits, of in de woorden van de Commissie in heffingsvrijstellingen.

\section{b De tarieven}

De Commissie Stevens stelt dus voor het aantal tariefschijven terug te brengen van drie naar twee. De hoogte van het inkomen waar men van de eerste tariefschijf overstapt naar de tweede tariefschijf is volledig bepaald door de inkomensplaatjes: de belastingplichtigen mogen er niet te veel op vooruit en niet te veel op achteruit gaan. De grens tussen de eerste en de tweede tariefschijf is gelegd bij $f$ 57.000,-. Daarbeneden geldt een 'gewoon' tarief; daarboven is het verhoogde tarief van toepassing. Door het optrekken van de inkomensgrens van de eerste tariefschijf van circa $f 43.000,-(1991)$ tot $f 57.000,-$, wordt bereikt dat $80 \%$ van de belastingplichtigen voortaan in de eerste tariefschijf valt (momenteel is dat circa $75 \%$ ). Teneinde de inkomenseffecten binnen de perken te houden hebben de inkomensplaatjes een belangrijke rol gespeeld bij de vaststelling van de hoogte van de tarieven.

De Commissie is tot de conclusie gekomen dat het tarief in de eerste tariefschijf 33,6\% kan bedragen, terwijl het tarief in de tweede tariefschijf gesteld wordt op $55 \%$.

Evenals momenteel het geval is, blijft de eerste tariefschiif bestaan uit twee gedeeltes, te weten de fiscale component en de premiecomponent. Op dit punt is bepaald geen vereenvoudiging bereikt; integendeel het wordt in die eerste schijf zelfs iets gecompliceerder: er wordt namelijk een

tweetal subschijven onderscheiden: de eerste subschijf loopt tot $f 46.500,-$ en bestaat uit een premiecomponent van $23,3 \%$ (momenteel $25,55 \%$ ) en een belastingcomponent van $10,3 \%$ (momenteel 13\%), te zamen dus 33,6\%. In het traject tussen $f$ 46.500,- en $f 57.000$,- is het tarief eveneens $33,6 \%$, maar dit percentage is alleen een fiscaal tarief. In de eerste subschijf bedraagt het premietarief voor 65 -plussers $8,1 \%$ (dit is momenteel $7,3 \%$ ); in totaal zijn zij dus in die eerste tariefschijf $18,4 \%$ verschuldigd. ${ }^{1}$

Het onderscheid tussen belasting- en premietarief is met name van belang voor situaties waarin iemand wel belastingplichtig is, maar niet verzekerd is in Nederland; ook in de gevallen dat er wel sprake is van verzekeringsplicht in Nederland, maar geen belastingplicht, speelt het onderscheid een rol.

Samengevat ontstaat dus het volgende beeld:

inkomen

tarief

$-f 46.500,-$

$f 46.500,--f 57.000,-$ $f 57.000-$

(a) voor 65 -plussers $8,1 \%$

Wanneer een bijzondere eenmalige bate wordt genoten is die doorgaans onderworpen aan een van de twee bijzondere tarieven (20\% en $45 \%$ ). De Commissie Stevens heeft evenwel geen voorstellen gedaan om deze bijzondere tarieven aan te passen. Met name zou te verwachten zijn dat het bijzondere tarief van $45 \%$ iets verlaagd zou worden.

Evenmin wordt voorgesteld de zogenoemde $80 \%$-regeling in de vermogensbelasting te wijzigen. Op grond van deze regeling is te zamen nooit meer aan inkomstenbelasting en vermogensbelasting verschuldigd dan $80 \%$ van het belastbaar inkomen. Het zou voor de hand liggend zijn om het $80 \%$ percentage in benedenwaartse richting aan te passen, nu het toptarief ook daalt van $60 \%$ tot $55 \%$. Overigens is er momenteel een wets- 


\section{MAB}

voorstel aanhangig dat erin voorziet dat het percentage van 80 wordt teruggebracht tot $75 \%$; dit vloeit onder meer nog voort uit de Oortse tariefverlaging.

\section{c De heffingsvrijstelling}

Alvorens het tarief toe te passen moet het inkomen nog verminderd worden met de belastingvrije som. De hoogte van de belastingvrije som is afhankelijk van de persoonlijke omstandigheden (gehuwd, samenwonend, alleenstaand, alleenstaande ouder). Elke belastingvrije som is ondergebracht in een eigen tariefgroep. Momenteel kennen we zes tariefgroepen; het is niet altijd even gemakkelijk vast te stellen in welke tariefgroep men is ingedeeld. De commissie stelt dan ook voor drie van de zes tariefgroepen af te schaffen. Dat heeft tot gevolg dat alleenstaanden voortaan geen recht meer hebben op een verhoogde belastingvrije som. Bovendien verandert de situatie voor alleenstaande ouders: zij krijgen voortaan recht op tweemaal de (nieuwe) heffingsvrijstelling.

Deze heffingsvrijstelling is een nieuw idee: momenteel wordt de belastingvrije som in mindering gebracht op het inkomen; daarna wordt daarop het tarief toegepast. Dat betekent dat de fiscale geldwaarde van de belastingvrije som hoger is naarmate het inkomen stijgt. De Commissie vindt dat niet terecht: ze is van oordeel dat voor iedereen de waarde van de belastingvrije som gelijk moet zijn. Daarom stelt zij voor het stelsel van belastingvrije sommen te verlaten en over te stappen op een zogenoemd tax-creditsysteem (de Commissie noemt dat overigens een heffingsvrijstelling). De heffingsvrijstelling komt niet in mindering op het belastbare inkomen, maar op de verschuldigde belasting. De Commissie vermeldt niet of dit bij een gering belastingbedrag kan leiden tot een teruggaaf van belasting; het is echter niet waarschijnlijk dat zij dat zou bedoelen.

De heffingsvrijstelling of basiskorting bedraagt $f 2.175$,- voor iedereen. Alleen 65-plussers hebben te maken met een lagere basiskorting, namelijk van $f$ 1.185,- . Dit hangt samen met het feit dat zij in de eerste tariefschijf minder belasting beta- len dan degenen die jonger zijn dan 65 jaar. Hun belastingwaarde van de huidige belastingvrije som is dan ook lager dan die van degenen die nog geen 65 jaar zijn; vandaar dat zij recht hebben op een lagere belastingaftrek. Er zijn geen bijzondere belastingaftrekken voor bepaalde bijzondere groepen belastingplichtigen zoals buitenlanders.

De voorgestelde heffingsvrijstellingen zien er als volgt uit:

- geen basiskorting (in verband met overdracht van de basiskorting aan de partner): $f 0,-$;

- éénmaal de basiskorting (tweeverdieners en alleenstaanden): $f 2.175,-$ of $f 1.185,-$;

- dubbele basiskorting (alleenverdieners en alleenstaande ouders): $f 4.350,-$ of $f 2.370,-$.

De systematiek van overdracht van de basiskorting verschilt niet van de huidige mogelijkheid tot overdracht van de basisaftrek tussen gehuwden en ongehuwd samenwonende partners.

Vorenstaande voorstellen dragen bij tot een verdere vereenvoudiging; dat geldt ook voor de tarieftoepassing in de loonheffing. Met name zal het invullen van de loonbelastingverklaring door werknemers voortaan een stuk gemakkelijker plaats kunnen vinden. Bezwaar is echter dat alleenstaande ouders er duidelijk op achteruit gaan. Het is de vraag in hoeverre dat politiek uiteindelijk haalbaar zal zijn; in elk geval zal het nog een hele opgaaf zijn om dat aan onze parlementariërs te 'verkopen'.

\section{De uitvoering}

De voorstellen leiden ertoe, zo heeft de Commissie berekend, dat het aantal belastingplichtigen dat nog in aanmerking komt voor het doen van een aangifte inkomstenbelasting met circa 500.000, afneemt. Wanneer dit cijfer juist zou zijn - de Commissie houdt ook zelf een slag om de arm - dan is dat zeker een substantiële vermindering te noemen die zowel voor de belastingplichtigen, als voor de belastingdienst alleen maar voordelig is.

Daar staat overigens wel tegenover dat er in de uitvoeringssfeer enige extra werkzaamheden terechtkomen bij de inhoudingsplichtigen, bij- 


\section{MAB}

voorbeeld doordat wordt voorgesteld het voordeel van het privégebruik van de ter beschikking gestelde auto, in de inhoudingssfeer te betrekken.

Veel belangrijker en ook ingrijpender zijn de voorstellen van de Commissie om de uitvoering van de loonheffing en de premieheffing werknemersverzekeringen in handen te leggen van een organisatie, te weten de fiscus. In de voorgestelde heffingsstructuur heft de fiscus zowel de loonbelasting als de premies waarna de fiscus de geïnde premies werknemersverzekeringen afdraagt aan de bedrijfsverenigingen. De vaststelling van de hoogte van de premies blijt in handen van de bedrijfsverenigingen. Ook de heffing en inning van andere bedragen die de bedrijfsverenigingen verzorgen (pensioen-en VUT-premies enzovoort), zullen overgaan naar de fiscus. Het zal duidelijk zijn dat dit voorstel een belangrijke efficiencyverbetering kan betekenen bij de uitvoeringsorganen en voor de werkgevers/inhoudingsplichtigen een duidelijke vereenvoudiging en kostenbesparing inhoudt. Deze vereenvoudiging gaat gepaard met het invoeren van een systeem waarbij de werkgever voor alle heffingen één aangifte behoeft te doen.

\section{Conclusie}

De Commissie Stevens heeft kans gezien om in een zeer beperkt tijdsbestek te komen tot een omvangrijk pakket maatregelen. Dat is bepaald een knappe prestatie. Daar staat echter tegenover dat de maatregelen niet altijd even goed doordacht zijn. Vooral waar het aankomt op de precieze uitwerking tasten we in een aantal gevallen nog in het duister. En dat is jammer. Bovendien speelt de huidige financiële positie van de BV Nederland de realisatie van de commissievoorstellen wellicht parten, vooral nu de plannen tot tariefverlaging gefinancierd moeten worden uit het schrappen van aftrekposten ter grootte van $f$ 10,6 miljard, terwijl daar op dit moment door de regering al $f 1,3$ miljard van is ingeboekt ten behoeve van lopende bezuinigingen. Het zal niet eenvoudig zijn dat geld ergens anders te vinden. En dat vermindert de kans op realisatie van de voorstellen aanzienlijk, vooral ook omdat de Commissievoorzitter zelf steeds gezegd heeft: het is alles of niets. Van dat laatste is hij inmiddels overigens al weer aardig teruggekomen. En terecht. Het wachten is nu op de door de reacties van de adviesorganen van de regering aan wie om commentaar is verzocht. Naar mag worden aangenomen zullen deze reacties in het voorjaar van 1992 bekend worden.

\section{Noot}

1 Bij de door de Commissie Stevens berekende percentages voor de premies is nog geen rekening gehouden met de tariefaanpassingen (-verhogingen) per 1 januari 1992. 